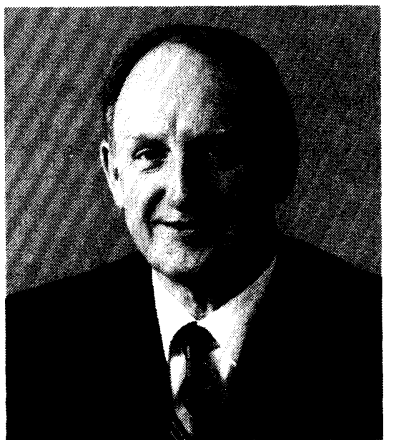

\section{International Partnering Showcase in Optics and Imaging}

Under the auspices of High Tech Global New York, a special two-day event titled "International Partnering Showcase in Optics and Imaging" will be held in Rochester, New York, on July 21-24, 1993. The program announcement for this event states that:

This summer in Rochester, New York, you will have the opportunity to forge new business alliances while interacting with a world-class community of university-industry professionals dedicated to the imaging technologies. Whether you are developing the next generation of products and processes, or engaged in leading-edge optics and imaging research and development, you should be attending the premier industry event.

This program coincides with Montage 93, a month-long International Festival of the Image. Montage "will celebrate the fusion of art and technology in contemporary imagemaking and explore the future of visual communications."

The program for the Partnering Showcase will consist of a Symposium on University-Industry Collaboration that will take place at the University of Rochester and is hosted by the University of Rochester and the Rochester Institute of Technology. Special panel presentations and project demonstrations will be held associated with New York's universityindustry centers including:

- University of Rochester's Center for Electronic Imaging Systems, Center for Advanced Optical Technology, Center for Optics Manufacturing, and Center for Photoinduced Charge Transfer;

- Rochester Institute of Technology's Center for Imaging Science and Center for Integrated Manufacturing Studies;

- Alfred University's Center for Advanced Ceramic Technology and Clarkson University's Center for Advanced Materials Processing.
The other major events of the three-day showcase include international industry seminars and formal business partnering sessions and an international trade show.

This whole program is part of Governor Mario M. Cuomo's Global New York Initiatives. The governor is inviting companies worldwide "to seek and find those opportunities for strategic business alliance or collaborative research that can spur new product development, sharpen the global competitive edge, and yield mutually beneficial and profitable results."

Governor Cuomo was in Rochester on February 24 to visit the University of Rochester's new Center for Optoelectronics and Imaging and the Eastman Kodak Company. I had the pleasure of spending a good part of the day with the governor.

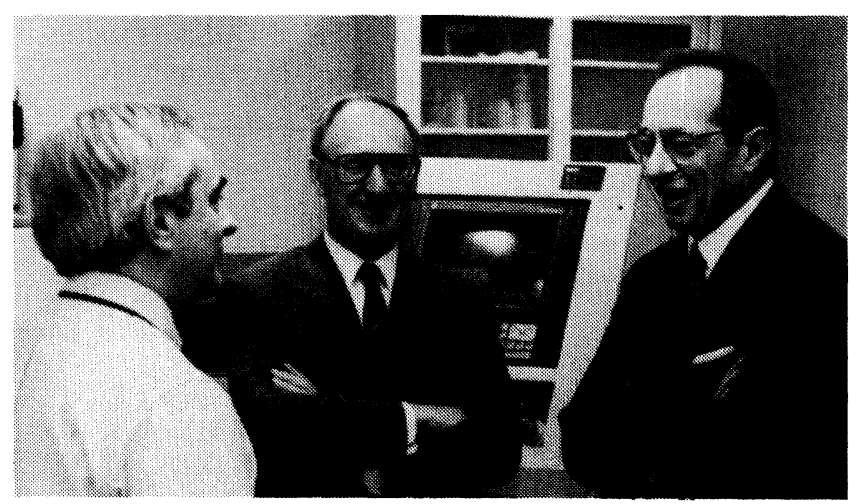

Left: Harvey Pollicove, director of the Center for Optics Manufacturing; center: Brian J. Thompson, provost of University of Rochester and editor of Optical Engineering; and right: Governor Mario Cuomo at the Center for Optoelectronics and Imaging at the University of Rochester (photograph by James Montanus).

During the press conference I had the opportunity to make some comments, which included the following:

We have an exemplary partnership in this region between the state, the academy, particularly the University of Roch- 
ester and Rochester Institute of Technology, and the industrial complex. This partnership is highlighted by the field of optics and imaging, an area of traditional ongoing strength. We are the optics and imaging capital of the world. The governor has been very supportive of these partnership activities and his 1994 initiatives in his State-of-the-State Address rally us all to be more hospitable to business, to promote emerging industries and strategic technologies, and to build on our strengths and technologies. We in academia, through our scholarly and research activities, are committed to supporting the governor's initiatives and look forward to our continuing partnership with the state and with industry.

These types of activities are very important to SPIE, because of its mission of technology transfer and the dissemination of information in optical science, engineering, and technology.

\section{A Weather Report!}

In my editorial in the May 1991 issue of Optical Engineering, I reported on the ice storm in Rochester-a storm that started on the afternoon of March 3. This year, we in Rochester thought that we would share our weather with the rest of the East Coast! The headlines from the Democrat and Chronicle for March 13-15 are shown opposite. An interesting event for us with 23.2 inches of snow, but it was only the "tenthgreatest storm in Rochester's history," according to meteorologist Kevin Williams in his articles in the Monday, March 15, editions of the Democrat and Chronicle. Williams goes on to note that 'the biggest storm in Rochester's history occurred March 1, 1900, with 43.5 inches of snow accumulating."

Unlike my report of the 1991 ice storm, we lost very little time in the office and, hence, work-time on Optical Engineering. Monday was certainly a lost day-I was stuck in Phila-

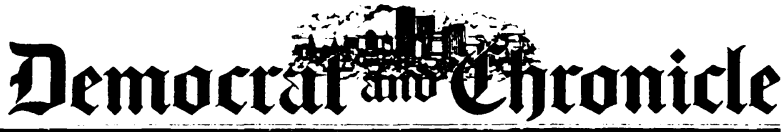

SATURDAY, MARCH 13,1993

Blizzard may wallop area

\section{Gusts up to $50 \mathrm{mph}$ predicted}

SUNDAY, MARCH $1+, 1993$
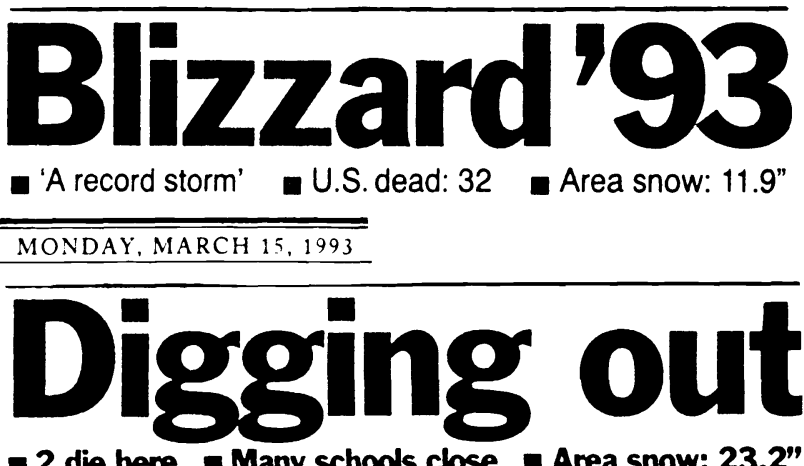

- 2 die here $\square$ Many schools close Area snow: 23.2"

delphia and did not get out until the early hours of Tuesday morning. The saving grace was that the incoming mail was light.

Postscript: We are fairly confident that the weather will be better on July 21-24 for the showcase!

Brian J. Thompson Editor 
June 1993

From Numerical to Symbolic Image Processing: Systems \& Applications G. Vernazza

Dipartimento di Ingegneria Biofisica ed Elettronica

Universita degli Studi di Genova

Via Opera Pia, 11a

16145 Genova, Italy

+39 $10353-2755 \bullet+3910353-2777$ FAX

July 1993

Visual Communication and Image

Processing IV

Cheng-Tie Chen

Bellcore

445 South St.

Morristown, NJ 07962

201/829-5151 • 201/829-5884 FAX

Hsueh-Ming Hang

Center for Telecommunication Research

National Chiao-Tung University

Hsinchu, Taiwan

$+886 / 35-712121 \times 3298 \bullet+886 / 35-723283$ FAX

Kou-Hu Tzou

COMSAT Labs.

22300 Comsat Drive

Clarksburg, MD 20871

301/428-4663 • 301/428-7747 FAX

September 1993

Optical Science and Engineering in Canada C.P. Grover

National Research Council

Institute for National Measurement Standards

Ottawa, Canada K1A OR6

613/993-2098 • 613/952-1394 FAX

October 1993

\section{Microlithography}

James R. Sheats

Hewlett-Packard Company

3500 Deer Creek Road

Palo Alto, CA 94304-1392

415/857-5987 • 415/857-2379 FAX

Optical Engineering in Hungary

Tivadar Lippenyi

HUNGOPTIKA

Tartsay u. 24

Budapest H-1120, Hungary

$3611563985 \cdot 3611563985$ FAX

Zoltan Fuzessy

Technical Univ. Budapest

Department of Physics

Balazs Bela u.36.IV.8

Budapest H-1094, Hungary

$3611666361 \cdot 3611666808$ FAX

November 1993

Acquisition, Tracking, and Pointing

Mohammed A. Karim

University of Dayton

Center for Electro-Optics

300 College Park

Dayton, Ohio 45469-0227

$513 / 229-2241 \cdot 513 / 229-3433$
December 1993

Magnetospheric Imagery and Atmospheric Remote Sensing

Supriya Chakrabarti

Boston University

Center for Space Physics

725 Commonwealth Avenue

Boston, MA 02215

E-mail: supc@bu-ast.bu.edu

617/353-5990 • 617/353-6463 FAX

January 1994

Infrared Technology

Marija S. Scholl

Alenlea Associates

P.O. Box 27408

Tempe, AZ 85285-7408

E-mail: msscholl@aol.com

602/491-7814

February 1994

Optical Interconnects and Packaging

Sing Lee

University of California/San Diego

E\&CE Department

La Jolla, CA 92093-0407

619/534-2413 • 619/534-1225 FAX

Manuscripts due July 1, 1993.

March 1994

High Heat Flux Optical Engineering

Ali M. Khounsary

Argonne National Laboratory

Advanced Photon Source, APS 362

Argonne, IL 60439

708/252-3384 • 708/252-3222 FAX

Manuscripts due Aug. 1, 1993.

April 1994

Optical Pattern Recognition

Joseph L. Horner

Rome Laboratory

EROP

Hanscom AFB, MA 01731-5000

617/377-3841 • 617/377-5041 FAX

Bahram Javidi

University of Connecticut

School of Engineering

Department of Electrical and Systems Engineering

Room 312, U-157

260 Glenbrook Road

Storrs, CT 06269-3157

203/486-4816 • 203/486-3789 FAX

Manuscripts due Sep. 1, 1993.

May 1994

Semiconductor Infrared Detectors

Antoni Rogalski

Institute of Technical Physics

Military Academy of Technology

Kaliskiego 2

00-489 Warsaw, Poland

$4822362109 \cdot 4822362254$ or 4822120757 FAX

Manuscripts due Oct. I, 1993.
June 1994

Optical Science \& Engineering in India

Rajpal S. Sirohi

Indian Institute of Technology

Applied Optics Laboratory

Physics Department

Madras-600 036, India

044-2351365 ext. 221 • 044-2350509 FAX

Manuscripts due Nov. 1, 1993.

July 1994

Adaptive Wavelet Transforms

Harold H. Szu

U.S. Navy

Naval Surface Warfare Center

Code R44

10901 New Hampshire Avenue

Silver Springs, MD 20903-5000

301/394-3097 • 301/394-3923 FAX

Manuscripts due Dec. 1, 1993.

August 1994

Digital Image Recovery and Synthesis

Paul S. Idell

Air Force Phillips Lab

PL/GPOA

390 B Great Road, \#18

Acton, MA 01720

612/377-3663 • 617/377-3661 FAX

Manuscripts due Dec. 1, 1993.

September 1994

Optics in South Africa

Hannes Markusse

ELOPTRO

Institute of Atomic Physics

P.O. Box 869

Kempton Park 1620, South Africa

Maurice W. McDowell

CSIR/Production Technology Div.

Productiontek

P.O. Box 395

Pretoria 0001, South Africa

$27128413418 \cdot 27128412131$ FAX

Manuscripts due Jan. 1, 1994.

October 1994

Optics in Russia

V. Ya. Panchenko

Scientific Research Center for Technological Lasers

Russia Academy of Sciences

B-333, Gubkina, 3

117971 Moscow, Russia

E-mail: ilc@compnet.npimsu.msk.su (095)135-54-30 • (095)334-02-01 FAX

Manuscripts due March 1, 1994.

November 1994

Micro-Optics

Chandrasekhar Roychoudhuri

University of Connecticut at Storrs

Photonics Research Center

MS-157, Room 312

260 Glenbrook Road

Storrs, CT 06269-3157

203/486-4816 - 203/486-3789 FAX

Manuscripts due April 1, 1994. 